East African Medical Journal Vol. 84 No. 2 February 2007

NOSOCOMIAL INFECTION IN A NIGERIAN RURAL MATERNITY CENTRE: A SERIES OF NINE CASES

O.A. Okezie, MBBS, FWACS, FICS, Consultant Obstetrician and Gynaecologist, University of Nigeria Teaching Hospital, Enugu and N.F. Onyemelukwe, BSc (Microbiol), MSc, Phd, Epidemiology and Public Health Microbiology, AIMLS, FIBMS, MI Biol. (London), Dean, Faculty of Health Sciences, College of Medicine, University of Nigeria, Enugu Campus, Nigeria

Request for reprints to: Dr. O.A. Okezie, Department of Obstetrics and Gynaecology, University of Nigeria Teaching Hospital, Enugu, Nigeria

\title{
NOSOCOMIAL INFECTION IN A NIGERIAN RURAL MATERNITY CENTRE: A SERIES OF NINE CASES
}

\author{
O.A. OKEZIE and N.F. ONYEMELUKWE
}

\begin{abstract}
Background: An outbreak of urinary tract infection in a rural maternity hospital near Enugu, Nigeria led to bacteriological assessment which identified Serratia marcescens as the causative organism. An epidemiological investigation was done to trace the source of this organism.

Objective: To investigate an outbreak of urinary tract infection in a rural maternity centre.

Design: A descriptive study.

Setting: Maternity centre in a rural community near Enugu run by local midwives assisted by auxillary nurses trained by the midwives.

Subjects: Nine patients at term with symptoms of urinary tract infection.

Results: In all nine cases, the pigmented form of Serratia marcescens was found to be the cause of the urinary tract infection and the source of this organism was traced to the auxillary nurse who shaved the patients and the instrument she used.

Conclusion: Since the causative organism of the outbreak of urinary infection in these women was traced to the shaving instruments used and the fingers of the auxillary nurse who shaved them, there is the need for better hygiene practices in the health centre and the use of properly trained staff to attend to pregnant and parturient women. It is recommended that the practice of shaving parturient women should be discarded.
\end{abstract}

\section{INTRODUCTION}

Nosocomial infections are health facility acquired infections. They occur more commonly in patients who have to remain for a length of time in the health facility for therapeutic or diagnostic reasons or for invasive procedures $(1,2)$. These infections may present with epidemic characteristics producing morbidity and mortality in patients who come to the health facility with less serious problems. It is necessary that the sources of such outbreaks be traced for purpose of effective control.

Serratia marcescens, a gram-negative bacillus belonging to the family enterobacteriaceae, was considered a non-pathogenic saprophtic water organism until late in the $20^{\text {th }}$ century (3). Its pathogenicity for humans was first noted in 1913; however, the prevalence of $S$. marcescens in human diseases had been underestimated for years before the first known outbreak of nosocomial S.marcescens infections in 1951. Since 1960, infections with this organism have been reported with increasing frequency.

S.marcescens is now recognised as a prominent opportunistic pathogen causing significant outbreaks of nosocomial infections of various severities, such as urinary infections (UTIs). Respiratory tract infections, bacteremia, conjuctivitis, endocarditis, 
meningitis, and wound infections $(1,4,5)$. In recent years, outbreaks associated with extended-spectrum $\beta$-lactamase producing or imipenem-resistant S.marcescens strains have emerged as an important infection control problem (3). Serratia marcescens infection has high resistance to anti-bacterial drugs (6). The source of such outbreaks could remain undisclosed $(4,5)$.

This work reports on an outbreak of urinary tract infection caused by a pigmented strain of $S$. marcescens that occurred in a local maternity cottage hospital in Owo-Emene, a rural community near Enugu, the capital city of Enugu State of Nigeria.

As part of our ongoing outreach epidemiological research in rural communities, we got a report from the midwife in charge of women with complaints of dysuria urinary frequency and urgency, loin pain and tenderness, all symptoms and signs of urinary tract infections. Four of the pregnant women attending antenatal clinic at the maternity home had been admitted at term for one problem or the other including lower back pain, fever, false labour, anaemia, gastroenteritis, hypertension, haemorrhage, etc, while seven had already delivered their babies few days earlier but were detained due to some debility or continuation of their pre-labour problems.

These women are simple housewives of poor village farmers who join their husbands on farm work. They are generally malnourished and grossly underfed and are usually multigravidae with average of six to eight previous deliveries. The reason for the high parity is the high infant mortality rate prevalence. This high parity takes its health toll on these women and added to their inability to provide good nutrition, they are more susceptible to infection. A total of 11 women were on admission in the maternity home during this study period

\section{MATERIALS AND METHODS}

Subjects: Owo-Emene is a rural community west of Enugu city, Enugu State, Eastern Nigeria. The local maternity cottage hospital was set up by communal effort to take care of child delivery in the community. Women living in the community patronised this maternity home. The 20-bed one-ward maternity home is run by local midwives with auxillary nurses trained by them. Once in awhile, women with serious complicated obstetric problems are discovered by the midwives and referred to bigger hospitals in nearby Enugu City.

Sample collection and analysis: Sterile borate urine containers (sterilin) were distributed to the women and the auxillary nurses instructed on how appropriate first morning midstream urine samples should be collected. Samples were taken to the Department of Medical Laboratory Sciences of the University of Nigeria, Enugu Campus within one hour of production for analysis.

Urine samples were cultured by standard bacteriological methods (7). Pure growth of Serratia marcescens of $\geq 10^{5}$ per mililitre of urine was identified by standard methods (Analytab API 20E), and antibiotic sensitivity tests were determined by agar dilution and Kirby-Bauer diffusion techniques $(8,9)$.

Tracing of source of infection: The epidemiological study consisted of interviews with the midwives and auxiliary nurses, a review of most common procedures (hand washing, disinfection, shaving methods, etc) culture of multiple samples from all the maternity home personnel and the environment including water supplies (metal containers and well water) soap, therapeutic solutions and antiseptics. Sixteen samples were collected from the hands of personnel, eight samples of antiseptic solutions, six samples of water from each source, swabs from window ledges, door handles, bed frames, tables, lockers, delivery room floor and the corridor railings. Charts of patients involved in the outbreak were also reviewed for clinical data such as temperature spikes and epidemiological data.

\section{RESULTS}

The investigation was carried out between $29^{\text {th }}$ January, 2005 and $7^{\text {th }}$ April, 2005. Within this period, of four pregnant women admitted in the maternity home at term due to some debility and other problems, two had severe urinary tract infection just before delivery, caused by a pigmented strain of $S$. marcescens. All the other seven women who were on admission post delivery also had UTI due to the same strain of organism.

All nine patients involved in the outbreak were aged between 26-42 years. The initial search for the origin of the outbreak, including interviews with 
the maternity staff, a review of the most common procedures and the use of multiple samples for culture was unsuccessful and failed to isolate S. marcescens.

Upon further interrogation of the midwife, a feature common to all these nine women were recorded. All patients involved in the outbreak had their pubic hair shaved by a particular auxiliary nurse whose duty it was to do so on all women admitted for childbirth.

The fact that all patients had been shaved by this auxiliary nursing staff led us to investigate the hands and the instruments of the auxiliary nurses and the shaving procedure of their patients. The three shaving sticks and razor blades in use were reusable and she continued to use same set for different patients and only discarded them when they became blunt due to excessive use. She was only using cotton wool and water to clean off the shaved hairs. These women lay flat in bed with their knees flexed and abducted to allow for shaving of their pubic areas. After one patient was shaved, the razor blade was brought out of the shaving stick and merely wiped with a common napkin and refixed for use on the next patient.

Pigmented strains of $S$. marcescens with the same biochemical characteristics as those isolated from the patient's urine samples were isolated from the hands and shaving sets (the razor blades and shaving stick) as well as the shaving brush of the auxiliary nurse.

Intervention: After suitable intervention measures were introduced (better hygiene, cleaning with antiseptics, use of disposable shaving sets for each patients, wearing of sterile gloves and face masks by the nursing staff during shaving and during delivery), further outbreaks terminated.

Antibiotic sensitivity tests: Antibiotic sensivity tests were done on the isolates. All the organisms presented with same biochemical pattern in API 20E (identification code 5307761) and the same antibiotic susceptibility pattern in the diffusion and agar dilution tests (Table 1). All isolates produced a cherry-red pigment. Patients were adequately treated with the results of the antibiogram.

Table 1

Antibiogram of the S.marcescens isolates from the UTI patients

\begin{tabular}{lcc}
\hline Antibiotic & $\mathrm{mic}(\mu \mathrm{g} / \mathrm{ml})$ & Susceptibility category \\
\hline Trimethoprim & $1 / 20$ & $\mathrm{MS}$ \\
Sulphamethoxazole $\leq$ & 8 & $\mathrm{~S}$ \\
Ceftazidime $\leq$ & 2 & $\mathrm{~S}$ \\
Gentamicin $\leq$ & 16 & $\mathrm{R}$ \\
Cefoxitin & 16 & $\mathrm{R}$ \\
Ampicillin $\geq$ & 2 & $\mathrm{~S}$ \\
Tobramycin $\leq$ & 16 & $\mathrm{R}$ \\
Cefazolin $\geq$ & 8 & $\mathrm{MS}$ \\
Cefotaxime $\leq$ & 4 & $\mathrm{~S}$ \\
Amikacin $\leq$ & & \\
\hline
\end{tabular}

$\mathrm{R}=$ Resistant, $\mathrm{MS}=$ Moderately susceptible $\mathrm{S}=$ Susceptible 


\section{DISCUSSION}

Nosocomial infections cause high morbidity and mortality especially when compromised patients are involved, and have an epidemic characteristic $(5,10)$. Epidemic outbreaks of nosocomial infections caused by $S$. marcescens, particularly in intensive care and neonatology units are well reported in literature $(3-5,11)$. The outcome of these infections are directly related to the underlying conditions as well as to the resistance of many Serratia strains to antimicrobial agents $(4,6)$. Our findings of many resistant strains are not very surprising particularly as antibiotics are freely sold over the counter in Nigeria and are prone to abuse.

S. marcescens has been incriminated in UTI amongst hospitalised patients by previous workers especially as opportunistic pathogens in the debilitated pregnant women $(12,13)$. According to Bachman (14) Chikwem et al (15), Isibor (16), UTI is a major cause of morbidity in pregnant women elsewhere and in Nigeria. This infection (UTI) is more common in females of all ages than in males, due to the shorter, wide female urethra, and in pregnancy because of the hormonal relaxation of smooth muscles and the pressure of the pregnant uterus on the urinary tract. This predisposes to obstruction in the tract causing stagnation of urine which then serves as a suitable culture medium for bacterial growth (16). Thus, in the current work, $S$. marcescens strains were involved in UTI among the debilitated pregnant women. Pregnancy on its own is a compromised state and in our patients, this is compounded by malnutrition and physical stress due to hardship and poverty as earlier mentioned.

It is probable from our finding, that the auxiliary nurse, during cleaning of the pubic region after shaving, might have transferred the organisms (probably contaminating the shaving sets and her hands) directly into the wide short urethra and immediate proliferation was favoured by the urine retained due to the pressure of the expanding uterus on the ureter. It is also not unlikely faecal materials could have been similarly transferred during the cleansing since the gastrointestinal tract has been shown to be a reservoir for Serratia strains $(4,17)$. The pregnant women may likely have contacted the UTI during their examination, occasional catheterisation and shaving process.
Sources of infection and mechanisms of transmission of this organism in the hospital are diverse and include contaminated intravenous solutions, scalp vein needles, surgical blades and hand washing brushes, catheters of different types and ultrasonic nebulisers $(5,12)$. In some occasion, sources and mechanisms of transmissions were not discovered $(4,17)$.

This outbreak was caused by a strain that produces cherry-red pigment as also recorded in cardiac and chest unit nosocomial infections by previous workers $(5,18)$. This finding is expected to be a rare event since almost all strains associated with human infections are non-pigmented $(5,19)$ and also noted that such strains are seldom isolated nowadays. Other workers elsewhere have also incriminated shaving brushes in epidemic nosocomial infections involving Serratia species and Pseudomonas species $(5,20)$.

In conclusion, it is therefore pertinent that more precautionary measures and strict hygienic practices are routinely adhered to in maternity procedures especially in rural setups. We recommend the need for more qualified personnel to be deployed to rural hospitals and also for routine visitations by external health teams is hereby stressed. The common practice of pubic and perineal shaving of parturient women should be discarded as there is no evidence of its usefulness, more so in this era of high prevalence of HIV, hepatitis and other infections.

\section{ACKNOWLEDGEMENTS}

To the staff of the Owo Community maternity home, Emene for co-operating with us; the laboratory staff of the Department of Medical Laboratory Sciences of the College of Medicine, University of Nigeria, Enugu Campus, where the laboratory work was done. We also thank the research students of Public Health Microbiology who also assisted in the sample collection and analysis.

\section{REFERENCES}

1. Dobson W.H. Serratia marcescens septicaemia. Arch. Int. Med. 1982; 121: 145-150.

2. Harley R.W., Tenney J.H., Lindsey II J.O., et al. How frequent are outbreaks of nosocomial infection in community hospitals? Infec. Control. 1985; 6: 166-174. 
3. Lin-Hui Su, Jonathan T.Ou, Hsieh-Shong Leu, et al. Extended epidermic of nosocomial urinary tract infections caused by Serratia marcescens. J. Clin. Microbiol. 2003; 41: 4726-4732.

4. Newport M.T., John J.F., Michel Y.M. and Levkoff A.H. Endemic Serratia marcescens infection in a neonatal intensive care nursery associated with gastrointestinal colonization. Paediat. Infec. Dis. 1985; 4: 160-167.

5. Wilhelmi I., Bernaldo D.E., Quiros J.C.L., et al. Epidemic outbreak of Serratia marcescens infection in a cardiac surgery unit. J. Clin. Microbiol. 1987; 25: 1298-1300.

6. Sleigh J.D. Antibiotic resistance in Serratia marcescens. Brit. Med. J. 1983; 287: 1651-1652.

7. Collee J.G. and Milesi W. Tests for the identification of bacteria. In J.G. Collee, J.P. Duguid, AG. Fraser and B.P. Marmion (ed.), Mackie and MeCartney Pract. Med. Microbiol. $13^{\text {th }}$ ed. Churchill Livingstone. 1989; 141-160.

8. Barry A.L and Thornsberry C. Susceptibility tests: Diffusion tests procedures. In: E.H. Lennette, A. Balows, W.J. Hausler Jr. and H.J. Shadomy (ed). Manual of Clinical Microbiology, 4th ed. Amer. Soc. Microbiol. Washington D.C. 1985; 978-987.

9. Washington J.A. Susceptibility tests: Agar dilution. In: E.H. Lennette, A. Balows, W.J. Hausler Jr., and H.J. Shadomy (ed), Manual of Clinical Microbiology, $4^{\text {th }}$ ed. Amer. Soc. Microbiol. Washington D.C. 1985; 967-971.

10. Wenzel R.P., Thompson R.L., Landry S.M., et al. Hospital-acquired infections in an intensive in an intensive care unit patients: An overview with emphasis on epidemics. Infec. Control. 1983; 4: 371-375.

11. Smith P.J., Brookfield S.K., Shaw D.A. and Gray J. An outbreak of Serratia marcescens infection in a neonatal unit. Lancet. 1984; 1: 151-153.
12. Okuda T., Endo N., Osada Y. and Zen-Yoji. Outbreak of nosocomial urinary tract infection caused by Serratia marcescens. J. Clin. Microbiol. 1984; 20: 691-695.

13. Sleigh J.D. and Duguid J.P. Enterobacteriaceae: Escherichia, klebsiella, proteus and other enterobacteria. In: J.G. Collee, J.P. Duguid, A.G. Fraser and B.P. Marmion (ed), Mackie and MeCartney, Practical Medical Microbiology, $13^{\text {th }}$ ed. Churchill Livingstone. 1989; 432-455.

14. Bachman J.W. Screening studies for asymptomatic urinary tract infection in Pregnancy. Lab. Medica xi. 1994; (3/4): 8-12.

15. Chikwem J.O., Ukwandu N.C.D., Ayuba K. and Edike M.A. Evaluation of Gram-stained smears of urine for prediction of significant bacteriuria. J. Med. Lab. Sci. 1996; 5: 49-53.

16. Isibor J.P. Laboratory diagnosis and treatment of urinary tract infection: A review. J. Med. Lab. Sci. 1997; 6: 15-19.

17. Christensen G.D., Korones S.B., Reed L., et al. Epidemic Serratia marcescens in a neonatal intensive care unit: importance of the gastrointestinal tract as a reservoir. Infec. Control. 1997; 3: 127-133.

18. Web S.F. and Val-Spinosa A. Outbreak of Serratia marcescens associated with the flexible fiberbronchoscope. Chest. 1976; 68: 703-708.

19. Platt D.J and Sommerville J.S. Serratia species isolated from patents in a general hospital. J. Hosp. Infec. 1981; 2: 341-348.

20. Whitby J.L., Blair J.N. and Rampling A. Cross-infection with Serratia marcescens in an intensive-therapy unit. Lancet. 1972; 2: 127-128. 